\title{
TRAUMA ABDOMINAL PENETRANTE CONSECUTIVO À CORRENTE ELÉTRICA INDUSTRIAL
}

\section{PENETRATING ABDOMINAL TRAUMA FOLLOWING INDUSTRIAL ELETRIC CURRENT}

\author{
Átila Varela Velho, TCBC-RS ${ }^{1}$ \\ José Luiz Strappazzon ${ }^{2}$ \\ Gémerson Gabiatti ${ }^{3}$
}

\section{INTRODUÇÃO}

Os ferimentos penetrantes de abdome produzidos por corrente elétrica são raros e são mais raros ainda aqueles que, penetrando a cavidade peritonial, produzem lesão visceral. Por esse motivo, há necessidade de que o cirurgião se mantenha atento e procure sempre avaliar a possibilidade de dano intra-abdominal em pacientes portadores de ferimentos elétricos localizados nessa região ou com suspeição clínica de que a corrente elétrica tenha por ali transitado. $\mathrm{O}$ tratamento apresenta algumas peculiaridades relativas à extensão do trauma e à amplitude do procedimento cirúrgico, devendo o cirurgião de trauma estar preparado para lidar com essas lesões.

\section{RELATO DO CASO}

Paciente masculino, branco, com 31 anos de idade, operador de rede elétrica, sofreu queimaduras após ter contato com um fio de alta voltagem no abdome. O atendimento inicial, realizado no local pelo Serviço de Atendimento Pré-hospitalar (SAMU), consistiu basicamente no transporte adequado ao centro de trauma. O paciente foi transportado ao Hospital de Pronto-Socorro Municipal (HPS) e se manteve estável hemodinamicamente (PA = 130 x 90mmHg; $\mathrm{FC}=90 \mathrm{bpm})$, sem alterações eletrocardiográficas ou ao exame neurológico (Glasgow 15).

Apresentava no hipocôndrio direito e mesogástrio uma extensa ferida, profunda, de formato estrelado, com $22 \mathrm{~cm}$ em seu maior eixo, pela qual havia exposição hepá- tica e de alças intestinais (Figura 1). Havia também múltiplas queimaduras de 2 o e 3 o graus nos membros superiores e inferiores esquerdos.

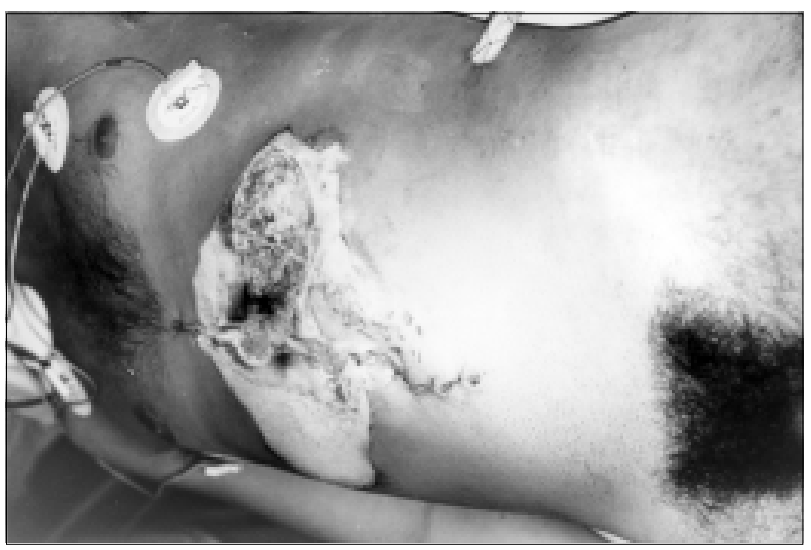

Figura 1 - Extensa ferida com exposição hepática e de alças instestinais.

O tratamento cirúrgico inicial, através de laparotomia obtida com a ampliação da ferida preexistente, e que revelou uma área de queimadura e desvitalização no lobo hepático esquerdo e na vesícula biliar, consistiu na ressecção do segmento hepático IV e na colecistectomia, seguidas de desbridamento da parede abdominal (restrito às áreas evidentemente desvitalizadas) e no fechamento primário da ferida.

1. Professor Assistente da FFFCMPA, Mestre em Gastroenterologia pela UFRGS, Preceptor da Residência em Cirurgia do Trauma do HPS

2. Cirurgião do Trauma do HPS

3. Residente em Cirurgia do Trauma do HPS

Recebido em 13/9/99

Aceito para publicação em 1/2/2000

Trabalho realizado no Serviço de Cirurgia do Trauma do Hospital de Pronto-Socorro Municipal de Porto Alegre (HPS) e na Fundação Faculdade Federal de Ciências Médicas de Porto Alegre (FFFCMPA) 
O paciente, que foi mantido com monitoração cardíaca e renal intensivas, recebeu alta da UTI no 4ㅇ dia de pósoperatório sem alterações das provas hepáticas, sem albuminúria, mas com a ferida operatória apresentando aspecto isquêmico. No 5o dia foi submetido a desbridamento de áreas necróticas das extremidades sob anestesia geral. No $6^{0}$ dia houve eliminação de secreção serosa-sanguinolenta através da ferida operatória que se acompanhava de evisceração bloqueada do conteúdo abdominal.

Essas alterações foram tratadas por imediata reintervenção cirúrgica, visando à correção do defeito da parede abdominal. Para isso, foi necessário o emprego de uma prótese de polipropileno (Marlex), fixada à aponeurose da bainha dos retos abdominais por pontos em $U$ de nylon monofilamentar, levado a efeito após ampla exposição dos bordos aponeuróticos e desbridamento cutâneo-musculoaponeurótico de pelo menos $1 \mathrm{~cm}$, além das zonas evidentemente desvitalizadas (Figura 2). Sobre a tela, a pele foi parcialmente aproximada, restando uma área central cruenta de aproximadamente $14 \mathrm{x} 9 \mathrm{~cm}$ recoberta por enxerto de pele no $22^{\circ}$ dia, quando já havia completo revestimento da prótese por tecido de granulação.

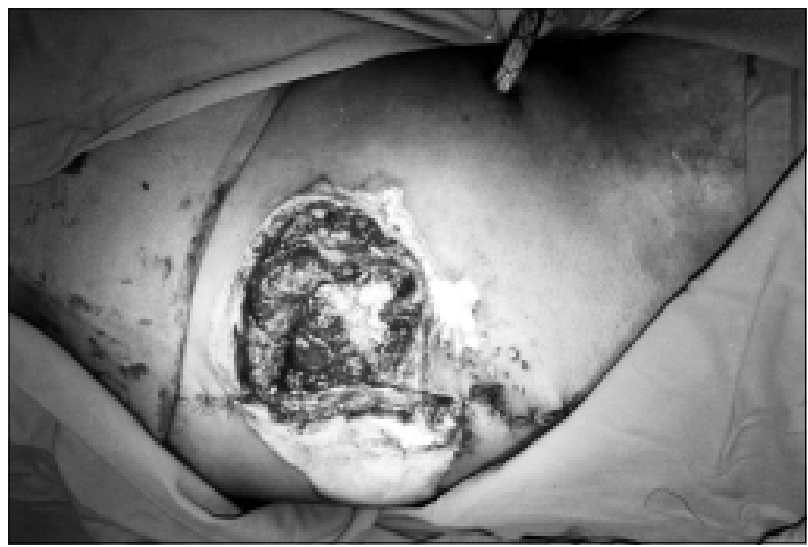

Figura 2 - Prótese de Marlex suturada a parede abdominal.

Durante vários dias foi necessário o desbridamento das lesões periféricas que cursaram sem infecção, tendo sido indicada apenas antibioticoprofilaxia com $1 \mathrm{~g}$ de cefoxitina $\mathrm{EV}$, na admissão. $\mathrm{O}$ tratamento obteve um resultado favorável e permitiu a alta hospitalar no 30 dia de pósoperatório. Não houve complicações durante seis meses de acompanhamento ambulatorial.

\section{DISCUSSÃO}

O primeiro relato de lesão visceral produzida por corrente elétrica data de 1927, quando Simonin descreveu um caso de perfuração de intestino delgado ${ }^{1,2}$. Desde então, encontramos apenas 16 relatos de lesão elétrica visceral descritos na literatura o que revela a raridade dessa condição.

Os ferimentos elétricos podem ser causados por correntes de baixa tensão, com voltagem menor que 1.000 volts, ou de alta tensão, com voltagem acima de 1.000 volts $^{1,3}$.
Tais ferimentos, manifestados sob a forma de queimaduras, ocorrem pela transformação da energia elétrica em calor quando em contato com os tecidos do organismo ${ }^{1,2,4}$, sendo mais elevadas as temperaturas nos locais de entrada e saída da corrente e mais graves as lesões nesses pontos ${ }^{2,5}$.

Nesse tipo de acidente, os locais mais freqüentes de entrada são os membros superiores e de saída as extremidades inferiores ou, mais raramente, o tronco ${ }^{2}$. Almgard et al. ${ }^{5}$ citam três casos de lesões cuja entrada encontrava-se na fossa ilíaca esquerda e na região sacral.

Em relação à extensão do ferimento, os fatores que a determinam são: a voltagem e a amperagem da corrente, a resistência tecidual e a área e a duração do contato ${ }^{1,4}$. Desses, os que mais influem na gravidade das lesões são a tensão da corrente e a área da superfície de contato.

Ferimentos abdominais podem ocorrer direta ou secundariamente à passagem da corrente elétrica pelo corpo, sendo o primeiro tipo mais comumente causado por correntes de alta tensão ${ }^{1}$. Neste relato, o trauma ocorreu diretamente, com o ponto de entrada da corrente no abdome superior, definido através da história e das características da lesão abdominal (bordos elevados, endurecidos, coloração branca e forma estrelada). $\mathrm{O}$ órgão mais acometido nos relatos existentes é o cólon, seguido pelo delgado ${ }^{1,2,3}$, os mais raros são: coração, esôfago, pâncreas, fígado e vesícula biliar ${ }^{1,2,4}$.

A existência de lesão hepática foi descrita uma única vez por Newsome et al. ${ }^{4}$ em 1972, em um operador de rede elétrica que teve contato direto do tórax com um fio de alta tensão e desenvolveu uma pequena lesão hepática e pancreatite aguda.

No presente caso, a necrose hepática apresentada era também de pequena proporção, fato atribuído por Newsome $e t a l .{ }^{4}$ à elevada resistência tecidual do fígado que limita a extensão da lesão.

Embora não tenhamos observado isso, uma afirmativa frequiente é de que a passagem da corrente elétrica pelo órgão causaria uma rápida e intensa elevação das enzimas ${ }^{5} \mathrm{o}$ que, segundo Branday et al. ${ }^{2}$, seria útil na detecção precoce da lesão. $\mathrm{O}$ acometimento da vesícula biliar é citado em outros relatos, mas não em simultaneidade com o fígado.

Após ter atingido o fígado e a vesícula biliar, a corrente elétrica parece ter saído pelas extremidades superior e inferior esquerdas, na forma de queimaduras de 20 grau. De uma maneira geral, o trajeto seguido pela corrente no organismo é inexato ${ }^{1}$, tendo a laparotomia exploradora o objetivo de identificar o caminho preciso e detectar alterações de vísceras abdominais que poderiam levar a complicações tardias.

Um ponto importante no tratamento é a reconstrução da parede abdominal. Após o reparo do ferimento, o paciente apresentou evisceração bloqueada de conteúdo abdominal, sendo reintervido para colocação de uma malha de MarlexR. Este fato nos leva a considerar, a exemplo do que fizeram Warde Filho et al. ${ }^{3}$, a necessidade de uma abordagem inicial mais agressiva da lesão de parede onde um desbridamento ampliado e o emprego de material protético para síntese da parede abdominal, ab initio, poderiam previnir reintervenções e a evisceração, fatores que podem agravar o prognóstico. 
Embora raro, o trauma abdominal por corrente elétrica carreia elevada morbimortalidade devendo ser levantada a suspeita de comprometimento visceral frente a esse quadro. A laparotomia exploradora pode ser im- portante e, quem sabe, a videolaparoscopia, na detecção precoce de lesões intracavitárias tanto na topografia da lesão dérmica quanto a distância, no percurso descrito pela corrente.

\begin{abstract}
The authors present a case report of a victim of high power electric shock. The main electric lesion was a penetrating abdominal wound with loss of substance of the abdominal wall and an electric lesion of the hepatic segment and of the gallbladder. The surgical treatment included hepatic segmentectomy, cholecystectomy, repair of the abdominal wall with Marlex prosthesis and skin graft, besides the debridment of the lesions of extremities. The postoperative evolution was satisfactory and the follow-up for 6 months didn't show any sequelae.
\end{abstract}

Key Words: Penetrating abdominal trauma; Electric current; Electric burns.

\section{REFERÊNCIAS}

1. Williams DB, Karl RC - Intestinal injury associated with low-voltage electrocution. J Trauma 1981; 21:24650.

2. Branday JM, DuQuesnay DR, Yeesing MT et al. - Visceral complications of electrical burn injury. W. I. Med. J. 1989; 38:110-13.

3. Warde Filho MJ, Duarte GG, Salles AG et al. - Trauma elétrico com evisceração e necrose de parede abdominal. Rev Col Bras Cir 1997; 24:41-41.

4. Newsome TW, Curreri W, Eurenius K - Visceral injuries An unusual complication of an electrical burn. Arch Surg 1972; 105:494-7.
5. Almgard LE, Liljedahl SO, Nylén B - Electric burns of the abdomen. Acta Chir Scand 1965;130:550-9

\section{ENDEREÇO PARA CORRESPONDÊNCIA}

Dr. Átila Varela Velho

Pr. Júlio de Castilhos, 20/sala 304

90430-020 - Porto Alegre-RS

Fone/Fax: (051)311-2008/3115244

E-mail: atila@pro.via-rs.com.br 